\title{
Learning by Exclusion in Toddlers ${ }^{1}$
}

\author{
Leylanne Martins Ribeiro de Souza ${ }^{2}$ \\ Universidade Federal \\ de São Carlos, \\ São Carlos-SP, Brazil
}

\author{
Maria Stella Coutinho de Alcantara Gil \\ Universidade Federal \\ de São Carlos, \\ São Carlos-SP, Brazil
}

\author{
Lucas Tadeu Garcia \\ Universidade Federal \\ de São Carlos, \\ São Carlos-SP, Brazil
}

\begin{abstract}
Children of different ages respond by exclusion in trials of auditory-visual conditional discriminations. However, the learning of these relations can depend on a variety of factors, such as age, vocabulary size and amount of exposure to the emerging relation. The present study assessed learning by exclusion in children aged between 16 and 24 months, using learning probes with and without mask that required either selection or rejection topographies. Familiar word-object conditional discriminations were taught to compose the baseline. Exclusion, learning, and control probes were used to test emergence, learning, and control by novelty in namereferent relations. Participants responded by exclusion but did not demonstrate consistent learning across all probes. Best performance occurred in learning probes that required control by selection. In the rejection probes, the participants consistently selected the novel stimulus. These results suggest that the type of probe used influences observed performance.
\end{abstract}

Keywords: stimulus control, learning, children, vocabulary

\section{Aprendizagem por Exclusão em Crianças Pequenas}

Resumo: Crianças de diferentes idades respondem por exclusão em discriminações condicionais auditivo-visuais. Entretanto, a aprendizagem desta relação pode depender de diversos fatores: idade, tamanho do vocabulário e número de exposições à relação emergente. $\mathrm{O}$ objetivo deste estudo foi avaliar a ocorrência de aprendizagem por exclusão em crianças de 16 a 24 meses, empregando sondas de aprendizagem, com e sem máscara, que requeriam ou topografias de seleção ou de rejeição, para identificar quais resultam em melhores desempenhos. Discriminações condicionais palavra-objeto familiares foram ensinadas para compor a linha de base. Sondas de exclusão, aprendizagem e controle verificaram a emergência, a aprendizagem e o controle pela novidade nas relações nome-referente. Os participantes responderam por exclusão, mas não apresentaram indícios de aprendizagem consistente entre as sondas. $O$ melhor desempenho ocorreu nas sondas de aprendizagem que requeriam controle por seleção. Nas sondas de rejeição, os participantes escolheram consistentemente o estímulo novo. Este resultado sugere que o tipo de sonda utilizado afeta o desempenho observado.

Palavras-chave: controle de estímulo, aprendizagem, crianças, vocabulário

\section{Aprendizaje por Exclusión en Niños Pequeños}

Resumen: Los niños de distintas edades responden por exclusión en discriminaciones auditivo-visuales condicionadas. Sin embargo, el aprendizaje de esta relación puede depender de múltiples factores: la edad, la amplitud del vocabulario y número de exposiciones a la relación emergente. El presente estudio tuvo como objetivo evaluar cómo ocurre el aprendizaje por exclusión en niños en las edades comprendidas entre los 16 y 24 meses, por medio de sondeos de aprendizaje con y sin máscara que requerían de topografías de selección o rechazo, para identificar cuales obtenían mejores desempeños. Las discriminaciones condicionadas de palabra-objeto familiar fueron instruidas para componer la línea de base. Las evaluaciones del aprendizaje ocurrían con y sin la máscara, lo que exigía mecanismos de respuesta por selección o por rechazo. Los sondeos de exclusión, aprendizaje y control verificaron la emergencia por la novedad en las relaciones nombre- referente. Los participantes respondieron por exclusión, pero no presentaron indicios de aprendizaje consistentes durante el desarrollo de las evaluaciones. El mejor desempeño fue verificado en los sondeos de aprendizaje que requerían de control por selección mientras que en los de rechazo, los participantes escogieron consistentemente el estímulo nuevo. Este resultado sugiere que el tipo de sondeo afecta el desempeño observado.

Palabras clave: control de estímulo, aprendizaje, niños, vocabulario

${ }^{1}$ Paper resulting from the Master's thesis of the first author, who was supervised by the second author and received advice from the third author, undertaken as part of the Graduate Program in Psychology at the Federal University of São Carlos. Support: Postgraduate research scholarship from the Coordination for the Improvement of Higher Education Personnel (CAPES); National Institute of Science and Technology on Behavior, Cognition, and Teaching (INCT-ECCE, acronym in Portuguese), the São Paulo Research Foundation (FAPESP - Grant No. 2014/50909-8); and the National Council for Scientific and Technological Development $(\mathrm{CNPq}$ Grant No. 465686/2014-1).

${ }^{2}$ Correspondence address: Universidade Federal de São Carlos. Centro de Educação e Ciências Humanas. Departamento de Psicologia. Rodovia Washington Luiz, Km 235, Monjolinho, São Carlos-SP, Brazil. Cx. Postal 676. CEP 13.565-905. E-mail: leylannemrs@yahoo.com.br
Studies involving arbitrary conditional discriminations describe exclusion responding as the immediate selection of a novel comparison stimulus (i.e., without a previously defined discriminative function) in the presence of a novel sample stimulus, when the novel comparison stimulus is presented among familiar comparison stimuli (i.e., with defined discriminative functions in relation to other sample stimuli). For example, if a child is presented with three objects (for example a ball and plane, the names of which are known by the child, and an unknown object) and the mother says: "Give the fulito (unknown name) to mummy", it is 
likely that the child will pick up the unknown object. The term "exclusion responding" was coined by Dixon (1977) to refer to the selection of a novel stimulus in such tasks, based on the assumption that the selection occurs due to the exclusion of the defined stimuli.

Given the relationship between this learning process and vocabulary acquisition, various studies have tested for selection by exclusion in toddlers, producing consistent results (Antoniazzi, Domeniconi, \& Schmidt, 2014; Barbosa, Gomes, Costa, \& Schmidt, 2015; Costa, Grisante, Domeniconi, de Rose, \& de Souza, 2013; Costa, Wilkinson, Mcllvane, \& de Souza, 2001; Domeniconi, Costa, de Souza, \& de Rose, 2007; J. Ribeiro \& Schmidt, 2015; Schmidt, Franco, Lotério, \& Gomes, 2016). These studies used different variations of matching-to-sample tasks, where discrete trials are performed in which a sample stimulus (usually a spoken word) is presented, immediately followed by two or more stimuli (usually objects or pictures) that serve as matching options. The tasks are performed either using a computer (Costa et al., 2001) or in a playful context using physical objects (Domeniconi et al., 2007).

Consistent results obtained by experiments using simple discrimination procedures conducted with dogs (Costa \& Domeniconi, 2012; Freitas, Reis, Mizael, \& Domeniconi, 2012; Zaine, Domeniconi, \& Costa, 2014; Zaine, Domeniconi, \& de Rose, 2016) and rats (Souza \& Schmidt, 2014) have confirmed the robustness of exclusion responding. However, there is still insufficient evidence to confirm that a single trial produces learning of the emergent relation (Costa, Domeniconi, \&de Souza, 2014; Costa et al., 2001). Experimentally, this means that, although the novel comparison stimulus may be selected in the presence of a novel sample stimulus in the exclusion probe, the conditional control is not maintained in later tests in matching-to-sample tasks.

Studies with children aged under 24 months have yielded varying results for learning by exclusion after a single trial, showing both negative (Garcia, 2010; Horst \& Samuelson, 2008) and positive results (Sertori, 2013). Although age has been shown to be an important factor influencing learning in tasks undertaken by children (Schmidt et al., 2016), some authors have discussed the effects of different types of learning probes on observed results (Costa et al., 2014).

With respect to learning probes, depending on the study, at least two comparison stimuli are presented and tests generally use what is conventionally called a "mask" or blank comparison stimuli. In a number of studies of exclusion responding, a mask was used to determine the nature of control by stimuli over novel stimuli selection in exclusion probes (Wilkinson \& Mcllvane, 1997).

When testing learning by exclusion is possible, for example, to present a novel stimulus as a sample stimulus and, among the comparison stimuli, the stimulus selected in the exclusion probe and another novel stimulus. The selection of the latter stimulus is indicative of learning, based on the hypothesis that the participant, having learned the relation between the sample and comparison stimuli in the exclusion probe, will reject that stimulus in the presence of a novel sample stimulus (control by S-). However, this selection may also be controlled by the novelty of the stimulus or by the fact that both the model and comparison stimuli are novel (control by $\mathrm{S}+$ ). Therefore, the selection of that stimulus does not necessarily indicate control or, ultimately, confirm learning. Replacing the novel comparison stimulus with the mask, which is generally done in the so-called Type 1 probes (Costa et al., 2014), shows whether the participant would reject the stimulus selected in the exclusion probe even when no novel stimulus is presented, confirming control by $\mathrm{S}$ - and making conclusions about learning more plausible.

Thus, two configurations can be used to test results: (1) A Type 2 probe without mask consisting of an undefined novel sample stimulus and comparison stimuli (defined, undefined from the exclusion probe, and novel undefined stimuli), with the correct response being the novel undefined stimulus; (2) A Type 4 probe without mask consisting of an undefined sample stimulus from the exclusion probe and comparison stimuli (defined, undefined from the exclusion probe and novel undefined stimulus), with the correct response being the undefined stimulus from the exclusion probe. Studies using mask have investigated two possible routes of control for testing learning: control by selection of novelty $(\mathrm{S}+)$ or by the rejection of defined stimuli (S-) (Costa et al., 2013; Wilkinson \& Mcllvane, 1997).

In certain types of probe (Type 4 probes), the undefined sample stimulus from the exclusion probe is dictated again and the child is exposed to the comparison stimuli previously selected in the exclusion probe, a second undefined stimulus and mask. If the relation established in the exclusion probe has been learned, the participant should select the comparison stimulus that matches the dictated sample stimulus and exclude the second undefined stimulus presented among the comparison stimuli ( $\mathrm{S}+$ controlling relation). In the Type 3 probe trial, the sample stimulus from the exclusion probe is dictated and the comparisons consist of a second undefined stimulus, a defined stimulus and mask, whereby the selection of the mask implies the exclusion of the second undefined stimulus presented among the comparison stimuli and a response in accordance with the relation that emerged in the exclusion probe (Scontrolling relation).

Probe trials conducted with children aged between 24 and 36 months using the mask procedure have produced different results. Type 4 probe trials have tended to achieve higher correct response rates than the other probes (ranging between a minimum of $72 \%$ in a study conducted by T.A. Ribeiro (2013) and maximum of $83 \%$ in a study undertaken by Sertori (2013)), while Type 3 probe trials have tended to yield lower correct response rates than the other probes (ranging between a minimum of $31 \%$ in a study conducted by T.A. Ribeiro (2013) and a maximum of $75 \%$ in a study undertaken by Costa et al. (2013)). 
Other studies with children aged under 24 months used Type 2 probes without mask (Garcia, 2010; Sertori, 2013) and Type 4 probes (Sertori, 2013). A study of children aged between 18 and 24 months conducted by Schmidt et al. (2016) showed that performance was inconsistent with learning using Type 1 and 3 probes, in contrast to Type 2 probes. According to the authors, the fact that in toddlers selection tends to be controlled by the presence of a novel stimulus may have affected participant performance, including the positive results in the Type 2 probes. This suggests that, although probes provide evidence of control by stimulus, the type of probe used may influence results. As a result, further research is required into the performance of toddlers in the different types of test trials designed to assess learning of conditional discriminations.

This study aimed to assess learning by exclusion among children aged between 16 and 24 months using learning probes with and without mask that required either selection or rejection topographies, in order to determine which result in better performance. The study was conducted in two stages: Stage 1, using standard procedure for testing exclusion responding (Garcia, 2010; Sertori, 2013); and Stage 2, using mask (Wilkinson \& McIlvane, 1997).

\section{Method}

\section{Participants}

Five girls aged between 16 and 24 months selected from a local day-care center participated in this experiment. The experimental sessions took place in a $9.45 \mathrm{~m}^{2}$ room in the local day-care center located near the nursery.

\section{Instruments}

The initial repertoire of the children was evaluated using three instruments:

The Denver II Developmental Screening Test (Frankenburg et al., 1990). The version translated and adapted for use in Portuguese by Pedromônico, Bragatto and Strobilus (1999) consists of 125 tasks that test children's development in four areas of functioning: fine motoradaptive, gross motor, personal-social, and language skills.

The Peabody Picture Vocabulary Test, revised edition (PPVT-R) (Dunn \& Dunn, 1981) used to assess the children's verbal repertoire (receptive vocabulary). The instrument consists of 175 vocabulary items of generally increasing difficulty.

Inventário Portage Operacionalizado (IPO). This version of the Portage Checklist (Bluma, Shearer, Frohman and Hilliard, 1976), translated and adapted for use in Portuguese by Williams and Aiello (2001), covers overall understanding in children aged between zero and six years in the following areas (580 items) - self help, language, social, cognitive and motor development.

\section{Material and equipment}

We used three toys used by the children on a daily basis and seven toys made from recycled materials as visual stimuli. The auditory stimuli consisted of names given to the toys used by the children on a daily basis (/auau/; /bola/; / tetê/ for baby bottle), while pseudo words were used for the toys made from recycled materials (/pafel; |tiba/; /xéde/; / nafu/; /bugul; /daga/; /mido/). Various toys were used in the playful activities at the end of the sessions.

The toys were shown in a "teaching notebook" developed by Minto de Sousa, Gil and Mcllvane (2015). Adapted for use in this study, the notebook consisted of 13 pages of spiral-bound black paper card. Pages with transparent, plastic pockets showing three-dimensional objects were interspersed with black monochrome pages shown during the intervals between trials. Page and plastic pocket width and height were 65 and $35 \mathrm{~cm}$ and 18 and 24 $\mathrm{cm}$, respectively. Spacing between the pockets was $3 \mathrm{~cm}$ and they were placed $10 \mathrm{~cm}$ from the top margin and $1 \mathrm{~cm}$ from the bottom margin. The sessions were recorded using a Sony ${ }^{\circledR}$ Handycam camcorder DCR-SR21.

\section{Procedure}

Data were collected after an initial three-week period of familiarization between the researchers and children. Data collection was undertaken at least once a week for a maximum period of five months. Each session lasted an average of five minutes and one session a day was conducted with each participant. During the sessions, the researcher and child were seated face to face with the teacher's notebook or toys placed between them. After finishing the tasks, the researcher and child engaged in two minutes of free play using different toys from the experimental stimuli.

Data collection. The procedure was divided into the following two stages: Stage 1-teaching of selection responses to an object in the teaching notebook, teaching of baseline conditional discriminations, and probes; and Stage 2 - teaching of responses to mask; teaching of baseline with mask, and probes with mask (Table 1).

Selection responses were taught using the matching-tosample procedure with sample stimuli and two comparison stimuli (Cos) and continuous reinforcement released in the form of praise and access to the toy. Incorrect responses were followed by a five-second period of silence (timeout) after which a new trial was started. Six trials were planned for each session. However, the mastery criterion was three consecutive correct responses, after which the session could cease. The procedure was performed in two sessions.

\section{Stage 1 - Procedure without mask stimulus}

Teaching of baseline conditional discriminations. Each trial was started with the following instruction: "(Name of the child), give me (name of the object)". Then, two comparison stimuli were presented (delayed matching-to- 
sample - DMTS). Teaching was initially performed within a continuous reinforcement schedule (CRF). The selection (pointing or touching) of the correct stimulus was followed by praise, such as "Very good!", “That's it!", and access to the object for around 60 seconds. Incorrect responses were followed by a period of silence and restriction of access to the object and then the start of a new trial. The mastery criterion was four consecutive correct responses. The sequence of trials was brought to an end if the child committed two consecutive errors. If the mastery criterion was not met, the session was repeated on the following day, using stimuli placed in different positions to those from the previous day, in order to balance the presentation of stimuli. If the criterion was met, the researcher went back to teaching the baseline with the same stimuli, but this time with the consequences released in a variable-ratio schedule (VR 2), in preparation for the exclusion probes.

Table 1

Experimental Design

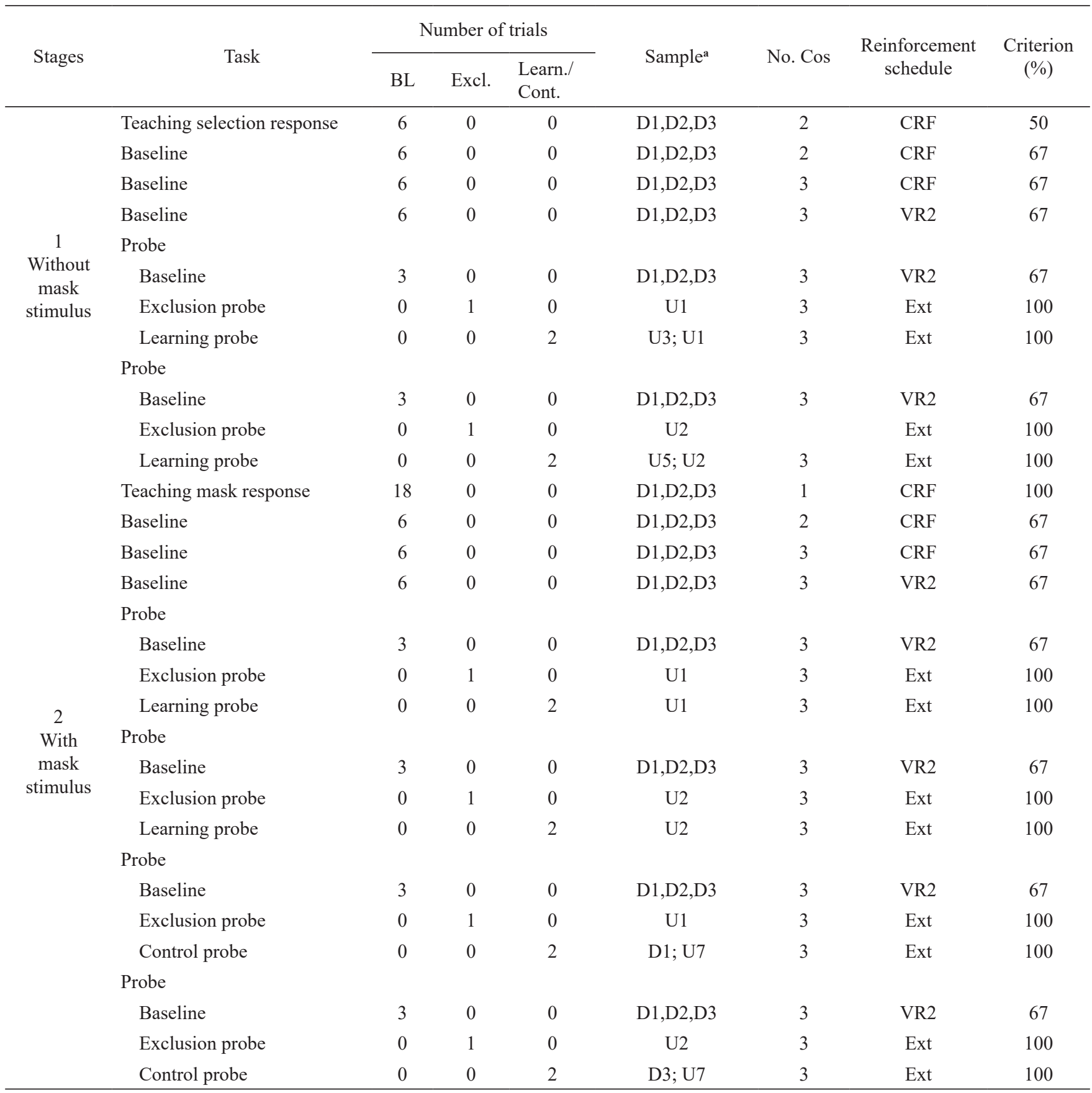

Note. $\mathrm{BL}=$ baseline $;$ Excl. $=$ exclusion $;$ Learn. $=$ learning $;$ Cont. $=$ control $; \mathrm{D}=$ defined stimulus; Cos $=$ comparison stimuli $; \mathrm{CRF}=$ continuous reinforcement; VR2 = variable-ratio schedule 2; Ext $=$ Extinction. ${ }^{a}$ Defined stimuli $-\mathrm{D} 1=a u a u ; \mathrm{D} 2=$ tetê; D3 = bola . Undefined Stimuli $\mathrm{U} 1=$ pafe; $\mathrm{U} 2=t i b a ; \mathrm{U} 3=x e ́ d e ; \mathrm{U} 4=n a f u ; \mathrm{U} 5=$ búgu; $\mathrm{U} 6=$ daga $; \mathrm{U} 7=$ mido. 
In cases where the child did not emit the selection response, the sample stimulus was repeated every six seconds for 30 seconds until the child touched or pointed to one of the pockets. If no response was given, a new trial was started. The following criteria were used to end sessions: consecutive correct responses in four trials; two errors in six trials; and situations in which the child became tired or irritated (e.g., child turning away from the researcher or crying) or took more than 30 seconds to emit a selection response.

Exclusion and learning probes. Each child was exposed to two sessions on different days. Each session consisted of six trials that tested exclusion responding and learning of two new auditory-visual relations ( $p a f e$ and $t i b a$ ). Each set consisted of three consecutive baseline trials, one exclusion probe and two learning probes. Four undefined sample stimuli (US1, US2, US3, and US4) and six undefined comparison stimuli (UC1, UC2, UC3, UC4, UC5, and UC6) used in the exclusion and learning probes. The baseline trials resulted in differential consequences for correct and incorrect responses and the exclusion and learning probes were conducted in extinction.

In the first exclusion trial, the US1was a spoken word (/ pafe/) and the comparison stimuli were the UCland two defined objects (DC2 and DC3). The selection of an undefined object was considered exclusion responding. In the first learning probe (Type 2, without mask), the US3 was a spoken word (/xéde/) and the comparison stimuli were UC3, DC3 and UC1. In the second learning probe (Type 4, without mask), the US1was presented as the sample stimulus and the comparison stimuli were DC1, $\mathrm{UC} 1$ and $\mathrm{UC} 4$. For these probes, the selection of $\mathrm{UC} 3$ and $\mathrm{UC1}$, respectively, were considered indicative of having learned the relation between the word /pafe/ and the matching object.

In the second exclusion trial, the US2 was a dictated word (/tiba/) and the comparison stimuli were the defined objects (DC2 and DC3) and UC2. In the first learning probe (Type 2, without mask), the US4 was a spoken word (/búgu/) and the Cos were UC5, DC1 and UC2. In the second learning probe (Type 4 probes, without mask), the US2 was the sample stimulus and the Cos were DC3, UC2 and UC6. The selection of UC5 and $\mathrm{UC2}$, respectively, were considered indicative of having learned the relation between the word /tiba/ and the matching object.

\section{Stage 2 - Procedure with Mask stimulus}

Teaching the response to the mask stimulus. The selection response to the opaque plastic pocket (that contained the object) was taught. The mask was "faded in" by gradually adding pieces of semi-semitransparent paper sheets between the pocket and the object, making the pocket more opaque over the course of the six trials (Sertori, 2013). This procedure was performed for each defined stimulus. Each stimulus was presented in six DMTS trials with only one Co and with CRF. The mastery criterion was $100 \%$ correct responses in six trials.

Teaching of baseline conditional discriminations with mask stimulus. The procedure was similar to that performed for teaching the baseline in Stage 1. Three conditional discriminations between words and defined objects were taught. The first six trials presented two comparison stimuli with $\mathrm{CRF}$ and, after meeting the criterion, another six trials were performed presenting three comparison stimuli with CRF. Then, another six trials presented three comparison stimuli with VR2. In half of the trials, the S+ was replaced by the blank comparison (mask). The mastery criterion was four consecutive correct responses in six trials.

Exclusion, learning and control probes. The exclusion and learning probes were similar to those performed in Stage 1 , differing due to the inclusion of the mask among the comparison stimuli in each trial and the addition of control probes, in which a new sample stimulus was presented. The mastery criterion for the baseline trials with VR2 was $67 \%$ of correct responses, while the exclusion, learning and control probes were conducted in extinction.

The six learning probe trials presented three comparison stimuli and were made up of: three baseline trials, one exclusion trial, and two learning trials. The same sample stimuli used in Stage 1 were used for the exclusion probe (the undefined words /pafe/ or /tiba/) and the Cos consisted of one defined object, one undefined object and a mask (opaque plastic pocket).

The first learning probe was a Type 4 probe, where the sample stimulus from the exclusion probe was presented again and the Cos consisted of the object selected in the exclusion probe (U1 or U2), a novel object and mask. In the second learning probe (Type 3 ), the sample stimulus from the exclusion probe was presented again and the comparison stimuli consisted of a defined stimulus, a second undefined stimulus, and a mask. The selection of the mask was considered indicative of learning.

The six control probe trials were made up of three baseline trials, one exclusion trial and two control probe trials. The exclusion probes were identical to those performed for the learning probes. The first control probe (Type A) tested whether responding was controlled by novelty. Defined sample stimulus from the baseline was presented and the Cos consisted of the defined object, one novel undefined object (UC7) and the mask. The selection of UC7 indicated that responding was controlled by novelty. The selection of the defined object indicated that the relation between the name-defined object was stable. The second control probe (Type B) tested whether exclusion responding occurs even when no novel stimulus was presented among the comparison stimuli. In this probe, the sample stimulus was a novel undefined word (/mido/), the Cos consisted of two defined comparison stimuli, and a mask. The selection of the mask indicated that the response was controlled by the undefined novel sample stimulus.

Data analysis. The responses in the baseline trials, exclusion probes, learning probes and control probes were monitored to determine the performance of the participant in relation to meeting the criterion for learning then over relation between the name and object. Participant performance and the possible routes of control of the stimuli used in each trial were analyzed for each type of learning probe. With regard to the reliability of the observations, all records of the sessions $(100 \%)$ were analyzed by two independent researchers in order to establish a coefficient of agreement between observers ([Agreements/ Agreements + Disagreements] x 100) in relation to the selection responses (Kazdin, 1982). The coefficient of agreement between the observers was $92 \%$. 


\section{Ethical Considerations}

The project was approved by the Human Research Ethics Committee of the Federal University of São Carlos (Approval number 182.010 of 12/11/2012). The study was also authorized by the director of the local day-care center and the participation of the children was authorized by their parents/guardians, who signed a free and informed consent form after being informed of the study objectives and tasks that the children would perform.

\section{Results}

The results of the Denver II Test (Pedromônico et al., 1999) showed that two participants (P1 and P3) presented risk in relation to the following general functions: language, gross motor and personal social. All participants presented normal development in the area of language (Peabody Picture Vocabulary Test) and with respect to the Inventário Portage Operacionalizado (Williams \& Aiello, 2001). The results of the PPVT-r (Dunn \& Dunn, 1981) showed that all children had a verbal repertoire in keeping with their age. The same instrument was applied at the end of the experiment, when two participants (P3 and P5) were shown to have a verbal repertoire that was smaller than that expected for their age.

All five participants completed all stages of the procedure. The number of sessions necessary for a participant to complete the procedure ranged between 17 and 33 sessions (P01: 33 sessions; P02: 28; P03: 24; P04: 17; and P05: 21). All participants learned all three baseline relations in Stage 1 and 2. Performance in the probes was described for each stage of the procedures and is summarized in Table 2.

\section{Stage 1 - Exclusion and learning probes without mask stimulus}

All participants consistently responded by exclusion in all probes, meaning they selected stimulus UC1 when presented with the word /pafe/ and stimulus UC2 when presented with the word /tiba/. All participants selected the correct stimulus in the learning trial (/pafe/) of the type 2 probe (the novel comparison stimulus (UC4) in the presence of the novel sample stimulus). Two participants (P01 and P05) selected the correct stimulus in the Type 4 probe trial (UC1 again when presented with the word /pafe/). In contrast, in the /tiba/ learning test, none of the participants presented a positive result in the Type 2 probe, despite two (P03 and P05) having indicated learning in the Type 4 probe. Four participants selected the object that matched /tibal (UC2) when presented with the novel sample stimulus and one selected a defined stimulus. All incorrect answers in the Type 4 probes corresponded to the selection of the novel object (UC4 or UC6) when presented with both sample stimuli in the exclusion probes (/pafe/ or /tiba/).

Table 2

Participants' responses in the learning and control probe trials - relations /pafe/ and /tiba/

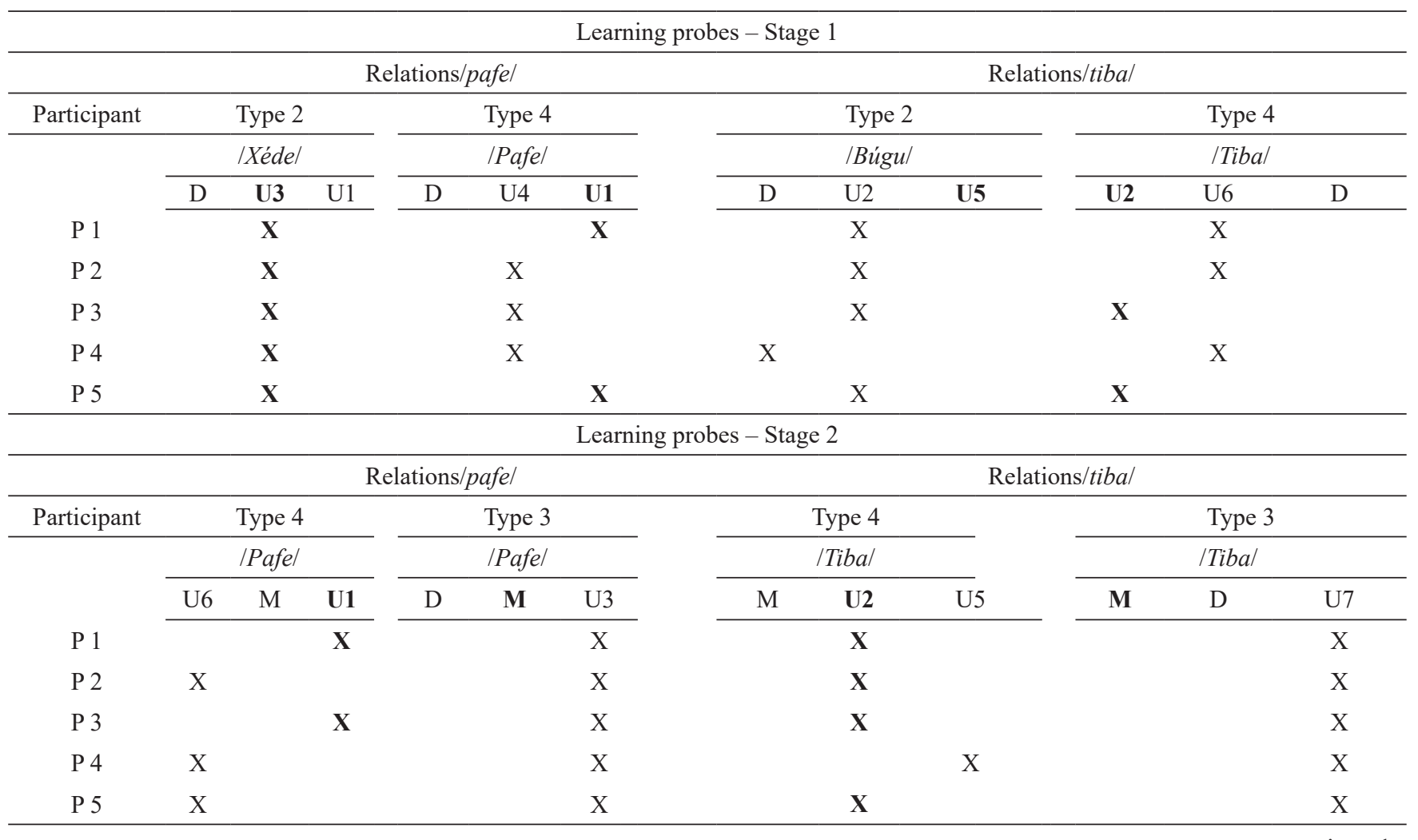


continuation...

\begin{tabular}{|c|c|c|c|c|c|c|c|c|c|c|c|c|}
\hline \multirow[b]{2}{*}{ Participant } & \multicolumn{6}{|c|}{ Relations/pafel } & \multicolumn{6}{|c|}{ Relations/tibal } \\
\hline & \multicolumn{3}{|c|}{ Type A } & \multicolumn{3}{|c|}{ Type B } & \multicolumn{3}{|c|}{ Type A } & \multicolumn{3}{|c|}{ Type B } \\
\hline & \multicolumn{3}{|c|}{ |Auaul } & \multicolumn{3}{|c|}{ /Mido/ } & \multicolumn{3}{|c|}{ |Bolal } & \multicolumn{3}{|c|}{ /Mido/ } \\
\hline & M & D & U4 & D & $\mathrm{D}$ & M & U4 & D & M & M & $\mathrm{D}$ & $\mathrm{D}$ \\
\hline P 1 & & $\mathbf{X}$ & & & & $\mathbf{X}$ & & & $\mathrm{X}$ & $\mathbf{X}$ & & \\
\hline P 2 & & & $\mathrm{X}$ & & & $\mathbf{X}$ & & $\mathbf{X}$ & & $\mathbf{x}$ & & \\
\hline P 3 & & $\mathbf{X}$ & & & $\mathrm{X}$ & & $\mathrm{X}$ & & & $\mathbf{X}$ & & \\
\hline P 4 & & & $\mathrm{X}$ & & & $\mathbf{X}$ & & & $\mathrm{X}$ & $\mathbf{X}$ & & \\
\hline P 5 & & $\mathbf{X}$ & & & & $\mathbf{X}$ & & $\mathbf{X}$ & & $\mathbf{X}$ & & \\
\hline
\end{tabular}

Notes. Defined stimuli - D1=auau; D2=tetê; D3= bola. Undefined stimuli $-\mathrm{U} 1=$ pafe; $\mathrm{U} 2=t i b a ; \mathrm{U} 3=x e ́ d e ; \mathrm{U} 4=$ nafu; U5= búgu; U6=daga; $\mathrm{U} 7=$ mido. $\mathrm{M}=$ mask stimulus. Letters in bold represent selections that indicate learning. The classification of the learning probes is based on Costa et al. (2014).

\section{Stage 2 - Exclusion, learning and control probes with mask stimulus}

The participants were aged as follows at the start of Stage 2: P01 - 23 months, P02 - 23 months, P03 - 25 months, P04 - 29 months, and P05 - 29 months. As in Stage 1, all participants selected the undefined stimuli UC1 and UC2 in the exclusion probes in which the spoken words /pafe/ and / tiba/ were presented as sample stimuli.

Two participants (P01 and P03) showed they had learned /pafe/ in the Type 4 probes (selecting UC1), while the others selected the novel stimulus. In the /tiba/ learning test, four participants (P01, P02, P03, P05) showed they had learned the word in the Type 4 probes and one (P04) selected the novel stimulus. In all Type 3 probes (with /pafe/ and /tiba/ as sample stimuli), all participants selected the novel undefined stimulus (none of the children selected a mask when the sample stimulus was repeated in the exclusion probe).

In the Type A control probes, which tested for control by novelty, P02, P03 and P04 selected the novel stimulus in the presence of the baseline sample stimulus. The other two participants (P01 and P04) selected the mask in the Type A control probe. In the Type $\mathrm{B}$ control probes, four participants (P01, P02, P04 and P05) responded by exclusion even in the absence of an undefined stimulus in the Cos matrix (i.e., they selected the mask when presented with an undefined sample stimulus when there were defined Cos in the selection matrix). One participant (P03) selected defined stimulus in the Type B control probe.

\section{Discussion}

The aim of this study was to assess learning by exclusion among children aged between 16 and 24 months using learning probes with and without mask that required either selection or rejection topographies, in order to determine which result in better performance. The results show regular and robust exclusion responding, corroborating the extensive literature on this subject (Costa et al., 2001; Dixon, 1977; T.A. Ribeiro, 2013; Sertori, 2013; Wilkinson \& McIlvane, 1997, among others). Also in line with the literature (Costa et al., 2014; T.A. Ribeiro, 2013), the learning results varied according to the type of test used, with Type 4 probes producing more positive results, followed by Type 3 probes.

The participants had difficulties in meeting the $100 \%$ correct response criterion for teaching baseline conditional discriminations. The average number of correct responses for six trials (two for each sample stimulus) varied between participants (P01: 3.66 correct responses; P02: 3.54; P03: 4.33; P04: 6, and P05: 4.83), while the ratios between correct responses and incorrect responses show that the criterion was very demanding. Since studies have shown that performance can deteriorate after constant exposure to the same set of stimuli (Oliveira \& Gil, 2008), it was decided to reduce the mastery criterion to four correct responses in six trials.

With regard to the test for exclusion responding, all children selected an undefined object when presented with the undefined words /pafe/ and /tiba/. Furthermore, in Stage 2 , four participants selected the mask when presented with the undefined spoken word /mido/ in the probes where the comparison stimuli consisted of a mask and two defined baseline objects. These results corroborate findings of other studies that show the generality of exclusion responding among toddlers, demonstrating that it occurs even in the absence of a novel object in the task (Costa et al., 2014; Wilkinson \& McIlvane, 1997).

However, participant performance in the learning probes varied according to probe type in both stages of the experiment. In Stage 1, in the learning test using the word Ipafe/, participants performed better in the Type 2 probes than in the Type 4 probes, except for those without mask. These findings are in line with the literature (Costa et al., 2014). However, in the learning test using the word /tiba/, performance in the Type 4 probes was more accurate than that in the Type 2 probes, in which all participants once again selected the object matching the word /tiba/, contradicting the findings of other studies. 
In Stage 2, the exclusion probes were identical to those used in Stage 1 and Type 4 probes ( $\mathrm{S}+$ controlling relation) and Type 3 (S- controlling relation) learning probes were used. The Type 4 and Type 3 probes correspond to the probe types described in the literature (Costa et al., 2014). In both arrangements, the sample stimulus from the exclusion probe was represented together with an undefined novel stimulus and the mask among the Cos. In the Type 4 probes, the stimulus selected in the exclusion probe was presented, while in the Type 3 probe, a defined stimulus from the baseline was presented (and the stimulus from the exclusion probe was under the mask). With regard to the word /pafe/, the results of the Type 2 and Type 4 probes (Stage 2) were similar in both stages, and there was no improvement in the learning results in the second stage, despite repeated exclusion trials. For /tiba/, the second application of the probes was followed by an improvement in learning results in relation to the first stage, from two to four positive results, which may be due to the fact that the children were re-exposed to the exclusion probes. In the Type 3 probe, however, the performance of the children was not indicative of learning for the relations / pafel and /tiba/. Although poorer performance is to be expected in this probe (Costa et al., 2014), it is necessary to analyze the factors that may have led to a null performance.

Almost all of the incorrect responses observed in the Type 4 and Type 3 learning probes, in both stages, corresponded to the selection of the undefined novel stimulus (the only exception being the selection of the defined stimulus by P04 in the Type 2 probe in Stage 1). This could be due to the effect of the novelty of the stimuli on the performance of the toddlers in tasks involving the selection of stimuli when presented with spoken names (Horst, Samuelson, Kucker, \& McMurray, 2011). Furthermore, three participant's selected the novel stimulus even when the sample stimulus presented was a baseline word and the defined matching stimulus was presented among the Cos.

These results suggest that, in attest of learning of a relation that emerged by exclusion, other sources of control over selection may overlap that which would typically be expected (Dube \& McIlvane, 1996). The findings of this study suggest that test format influences probe results. In other words, although the inclusion of undefined stimuli in these probes serves as an important parameter for testing learning of the relation between the sample and comparison stimuli of the exclusion probe, it could also introduce incompatible sources of control, thus impairing overall results.

The results of the Type 2 probes (Stage 1) could be partially explained by control by novelty, given that a second pair of undefined sample and comparison stimuli was presented (Garcia, 2010). Thus, the fact that the results indicate control by novelty suggests that the expected and obtained learning results from this type of probe should be considered with caution. Studies should therefore use other methods for testing the acquisition of new repertoires by exclusion in such tasks, such the conditional discrimination tasks used by Dixon (1977).

Preference for a specific stimulus, frequently observed in studies of discriminative repertoires among children of this age (Minto de Sousa, Garcia, \& Gil, 2015; Oliveira \&
Gil, 2008), may have affected some of the observed results. In the Type 2 and Type 4 learning probes (Stage 2) for the relation /tiba/, where the object UC5 (búgu) was presented as a comparison stimulus together with object UC2 (tiba), UC5 was selected only once. The consistency of performance in these probes may reflect a possible preference for the object related to the word /tiba/ or a low preference for UC5. This effect may also explain the anomalous result in the Type 2 probe in Stage 1, where four participants selected /tiba/ once again and one participant selected a defined object.

The results of the language section of the IPO have been shown to be predictors of better results in the learning probes. However, this relation was not corroborated by the present study, since the results only partially confirm learning. Based on the results of the PPVT-R, the level of vocabulary knowledge of two participants at the end of the experiment less than would be expected at their age may be an important indicator of learning by exclusion. It may be assumed that the level of receptive vocabulary knowledge affects new learning after minimal exposure to exclusion (Greer \& Du, 2015; Schmidt et al., 2016), which is a hypothesis that requires empirical evidence. Accordingly, the vocabulary of children closer to 30 months should be proportionally greater than that of the younger children, which in turn may favor learning of words after few exposures.

One of the limitations of this study is the use of the same word-object relations in both Stage 1 and 2, given that in Stage 2 all participants had already had contact with the undefined words and their matching objects. In Stage 2, it could be said that there was a "re-exposure" to trials that were similar to the exclusion trial. It is suggested that in future studies the quantity of undefined word-object relations should be increased.

The results of this study provide further evidence supporting the generality of the phenomenon of exclusion responding in children aged between 16 and 24 months, demonstrating its occurrence regardless of the presentation of a novel stimulus among the Cos. The fact that the results only partially confirm learning, partially corroborate the findings of other studies (T.A. Ribeiro, 2013; Sertori, 2013), suggesting that procedures need to be improved. The findings also suggest that, among toddlers, conflicting sources of control (Dube \& McIlvane, 1996) - such as preference for novel stimuli - may come into play in trials designed to test learning. The improvement of learning assessment methods would allow a better understanding of this phenomenon among young children and help define teaching procedures, and should be the focus of future research into learning by exclusion among this population group.

\section{References}

Antoniazzi, M., Domeniconi, C., \& Schmidt, A. (2014). Efeito da pré-exposição ao objeto no desempenho por exclusão e na aprendizagem da relação nome-objeto [Effect of object pre-exposure on exclusion performance and name-object relation learning]. Acta Comportamentalia, 22(1), 23-36. 
Barbosa, B. F., Gomes, G. F., Costa, A. A., \& Schmidt, A. (2015). Aprendizagem de discriminação auditivo-visual a partir de uma única tentativa de exclusão com objetos tridimensionais [Learning auditory-visual discrimination from a single exclusion trial with three-dimensional objects]. Revista Brasileira de Terapia Comportamental e Cognitiva, 17(3), 22-37.

Bluma, S., Shearer, M., Frohman, A., \& Hilliard, J. (1976). Portage guide to early education. Portage, WI: Cooperative Educational Service Agency.

Costa, A. R. A., \& Domeniconi, C. (2012). Análise do responder por exclusão por um cão treinado em tarefas de discriminação simples [Analysis of exclusion responding in a dog trained in simple discrimination tasks]. Revista Brasileira de Análise do Comportamento, 5(1), 49-62. doi:10.18542/rebac.v5U1.721.

Costa, A. R. A., Domeniconi, C., \& de Souza, D. G. (2014). Controle de estímulos, mapeamento simbólico emergente e aquisição de vocabulário [Stimulus control, emergent symbolic mapping and vocabulary acquisition]. In J. C. Rose, M. S. C. A. Gil, \& D. G. Souza (Orgs.), Comportamento simbólico: Bases conceituais e empiricas [Symbolic behavior: Conceptual and empirical basis] (pp. 269-308). Marília, SP: Oficina Universitária. São Paulo: Cultura Acadêmica.

Costa, A. R. A., Grisante, P. C., Domeniconi, C., de Rose, J. C. C., \& de Souza, D. G. (2013). Naming new stimuli after selection by exclusion. Paidéia (Ribeirão Preto), 23(55), 217-224. doi:10.1590/1982-43272355201309

Costa, A. R. A., Wilkinson, K. M., McIlvane, W. J., \& de Souza, D. G. (2001). Emergent word object mapping by children: Further studies using the blank comparison technique. The Psychological Record, 51(3), 343355. Retrieved from http://opensiuc.lib.siu.edu/cgi/ viewcontent.cgi?article $=1321 \&$ context $=\mathrm{tpr}$

Dixon, L. S. (1977). The nature of control by spoken words over visual stimulus selection. Journal of the Experimental Analysis of Behavior, 27(3), 433-442. doi:10.1901/jeab.1977.27-433

Domeniconi, C., Costa, A. R. A., de Souza, D. G., \& de Rose, J. C. (2007). Responder por exclusão em crianças de 2 a 3 anos em uma situação de brincadeira [Exclusion responding by 2 - to 3 -years-old children in a play setting]. Psicologia: Reflexão e Crítica, 20(2), 342-350. doi:10.1590/S0102-79722007000200021

Dube, W. V., \& McIlvane, W. J. (1996). Implications of a stimulus control topography analysis for emergent stimulus classes. In T. R. Zentall \& P. M. Smeets (Eds.), Stimulus class formation in humans and animals (pp. 197-218). Amsterdam, The Netherlands: Elsevier.
Dunn, L. M., \& Dunn, L. M. (1981). Manual for the Peabody Picture Vocabulary Test - Revised. Circle Pines, MN: American Guidance Service.

Frankenburg, K. W., Dodds, J., Archer, P., Bresnick, B., Maschka, P., Edelman, N., \& Shapiro, H.(1990). Denver II: Technical manual. Denver, CO: Denver Developmental Materials.

Freitas, M. C., Reis, T. S., Mizael, T. M., \& Domeniconi, C. (2012). Responder de cães por exclusão em tarefas de discriminação condicional [Conditional discrimination responding by exclusion in dogs]. Interação em Psicologia, 16(2), 173-183. doi:10.5380/psi.v16U2.21938

Garcia, L. T. (2010). Ensino de discriminações condicionais em bebês: Avaliação do responder por exclusão e treino de emparelhamento de identidade com diferentes estimulos [Teaching conditional discriminations in babies: Assessment of exclusion responding and identity matching training with dissimilar stimuli] (Master's thesis). Retrieved from https://repositorio. ufscar.br/bitstream/handle/ufscar/6011/3189. pdf? sequence $=1$ \&isAllowed $=\mathrm{y}$

Greer, R. D., \& Du, L. (2015). Experience and the onset of the capability to learn names incidentally by exclusion. The Psychological Record, 65(2), 355-373. doi:10.1007/ s40732-014-0111-2

Horst, J. S., \& Samuelson, L. K. (2008). Fast mapping but poor retention by 24-month-old infants. Infancy, 13(2), 128-157. doi: 10.1080/15250000701795598

Horst, J. S., Samuelson, L. K., Kucker, S. C., \& McMurray, B. (2011). What's new? Children prefer novelty in referent selection. Cognition, 118(2), 234-244. doi:10.1016/j. cognition.2010.10.015

Kazdin, A. E. (1982). Single-case research designs: Methods for clinical and applied settings. New York, NY: Oxford University Press.

Minto de Sousa, N., Garcia, L. T., \& Gil, M. S. C. A. (2015). Differential reinforcement in simple discrimination learning in 10- to 20-month-old toddlers. The Psychological Record, 65(1), 31-40. doi:10.1007/ s40732-014-0081-4

Minto de Sousa, N., Gil, M. S. C. A., \& Mcllvane, W. J. (2015). Discrimination and reversal learning by toddlers aged 15-23 months. The Psychological Record, 65(1), 41-47. doi:10.1007/s40732-014-0084-1

Oliveira, T. P., \& Gil, M. S. C. A. (2008). Condições experimentais facilitadoras para a aprendizagem de discriminação por bebês [Experimental conditions to facilitate infants discrimination learning]. Psicologia: Teoria e Pesquisa, 24(1), 5-18. doi:10.1590/S010237722008000100002 
Pedromônico, M. R. N., Bragatto, E. L., \& Strobilus, R. (1999). Teste de Triagem Denver II [Denver Developmental Screening Test II]. São Paulo, SP: UNIFESP.

Ribeiro, J., \& Schmidt, A. (2015). Aprendizagem de relações palavra-objeto por bebês em um procedimento de introdução sucessiva de estímulos [Learnig of wordobject relations in infants in a sucessive introduction of stimulus procedure]. Revista Brasileira de Análise do Comportamento, 11(1), 70-79. doi:10.18542/rebac. v11U1.3777

Ribeiro, T. A. (2013). Responder por exclusão na aprendizagem de relações simbólicas envolvendo adjetivos [Learning symbolic relations (word-qualifiers) by exclusion] (Master's thesis). Retrieved from https:// repositorio.ufscar.br/bitstream/handle/ufscar/6039/5022. pdf? sequence $=1 \&$ isAllowed $=y$

Schmidt, A., Franco, M. G. O., Lotério, L. S., \& Gomes, G. F. (2016). Learning name-object relations after a single exclusion trial in 18- to 48-month-old children. The Psychological Record, 66(1), 53-63. doi:10.1007/ s40732-015-0151-2

Sertori, N. M. (2013). Discriminações condicionais em bebês de risco: $O$ responder por exclusão [Conditional discrimination in infants at risk: Exclusion responding] (Master's thesis), Retrieved from https://repositorio. ufscar.br/bitstream/handle/ufscar/3 143/5297. pdf? sequence $=1$ \&isAllowed $=y$

Souza, M. F., \& Schmidt, A. (2014). Responding by exclusion in Wistar rats in a simultaneous visual discrimination task. Journal of the Experimental Analysis of Behavior, 102(3), 346-352. doi:10.1002/jeab.106

Wilkinson, K. M., \& Mcllvane, W. J. (1997). Blank comparison analysis of emergent symbolic mapping by young children. Journal of Experimental Child Psychology, 67(2), 115-130. doi:10.1006/jecp.1997.2402

Williams, L. C. A., \& Aiello, A. L. R. (2001). O Inventário Portage Operacionalizado: Intervenção com famílias [The Inventário Portage Operacionalizado: Intervention with families]. São Paulo, SP: Memnon/FAPESP.

Zaine, I., Domeniconi, C., \& Costa, A. R. A. (2014). Exclusion performance in visual simple discrimination in dogs - Canis familiaris. Psychology \& Neuroscience, 7(2), 199-206. doi:10.3922/j.psns.2014.014

Zaine, I., Domeniconi, C., \& de Rose, J. C. (2016). Exclusion performance and learning by exclusion in dogs. Journal of the Experimental Analysis of Behavior, 105(3), 362-374. doi:10.1002/jeab.209
Leylanne Martins Ribeiro de Souza is a Ph.D. candidate in the Graduate Program in Psychology at Universidade Federal de São Carlos.

Maria Stella Coutinho de Alcantara Gil is an Associate Professor at Universidade Federal de São Carlos.

Lucas Tadeu Garcia is a Professor at Universidade Federal de São Carlos.

Received: Jul. 08, 2016

1st Revision: Oct. 05, 2016

Approved: Dec. 06, 2016

How to cite this article:

Ribeiro de Souza, L. M., Gil, M. S. C. A., \& Garcia, L. T. (2018). Learning by exclusion in toddlers. Paidéia (Ribeirão Preto), 28, e2810. doi: http://dx.doi.org/10.1590/1982-4327e2810 